\title{
Gesichtsfalten reduzieren, Zellgesundheit fördern
}

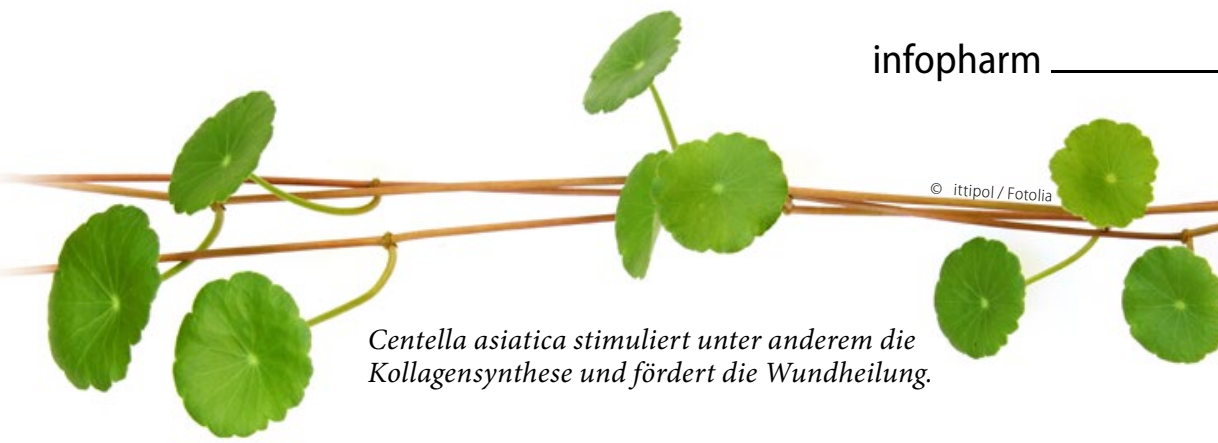

Das Youth Serum ${ }^{\mathrm{TN}}$ führte in einer klinischen Studie des Hamburger Forschungsinstituts SIT Skin Investigation and Technology zu einer signifikanten Steigerung der Kollagensynthese von Fibroblasten. Es bewirkt eine rasche Glättung und Straffung sowie eine deutliche Verminderung der Falten im Laufe der Zeit. Proteine konzentrieren sich auf angegriffene Partien, kräftigen die Hautstruktur und glätten feine Linien. Zugleich bauen die darin enthaltenen naturidentischen Wachstumsfaktoren Kollagen wieder auf, um feine Linien und Falten langfristig zu reduzieren. Die patentierte Extremozyme ${ }^{\circledast}$-Technologie fördert zusammen mit einer Mischung aus Antioxidantien und Tigergras (Cen- tella asiatica) die Zellgesundheit, bietet UV-Schutz und verhindert Schäden durch Umweltbelastungen. Die Anwendung ist parabenfrei und auch für die Augenpartie geeignet. 1-2 Tropfen pro Anwendung reichen aus. Weitere Informationen unter www.is-clinical.de.

Nach Informationen von EcoMedic

\section{An Sonnenschutz denken}

In der Urlaubszeit denken wir ganz automatisch an einen ausreichenden Sonnenschutz. Doch was ist eigentlich mit dem Rest des Jahres? Die Intensität der UVStrahlung ist nicht immer gleich, sondern hängt vom Sonnenstand, der Jahresund Tageszeit, der Bewölkung, der Ozonschicht und der geografischen Lage ab. So ist die UV-Strahlung um die Mittagszeit im Sommer fast fünfmal so stark wie im Winter. Dichte Wolken können die Strahlung zwar reduzieren, aber nicht abblocken. Leichte Bewölkung bietet überhaupt keinen Schutz.
UV-Strahlung kann unsere Haut nachhaltig schädigen, weil sie die Erbinformationen unserer Hautzellen verändert. UV-A-Strahlen dringen tief in die Haut ein und sorgen für eine sofortige, kurzfristige Bräune. Auf die Dauer führen sie aber auch zu Hautalterung und Faltenbildung, sowie zu Schäden im Erbgut. UVB-Strahlen hingegen sind kurzwellige, energiereiche Strahlen, die vor allem auf die oberen Hautschichten wirken. Sie führen zu einer langsamen, anhaltenden Bräune, weil sie die Melanin-Produktion stimulieren, können aber auch Sonnen- brand verursachen. Das Risiko an hellem Hautkrebs zu erkranken steigt.

Man sollte seine Haut also am besten ganzjährig vor negativen Einflüssen schützen. Das gilt insbesondere für Risikogruppen, wie z.B. Outdoorworker oder Menschen mit Vorerkrankungen. Der Sonnenschutz sollte über einen Lichtschutzfaktor 50+ verfügen und sowohl UV-A- als auch UV-B-Strahlung abwehren. Actinica Lotion verfügt über LSF $50+$ und unterstützt nachgewiesenermaßen die Prävention von hellem Hautkrebs. Die Lotion ist frei von Duftstoffen und PEG-Emulgatoren und deshalb für alle Hauttypen geeignet, auch für besonders sensible Haut.

Nach Informationen von Galderma

\section{Hyaluronsäurefiller erhält die Dynamik des Gesichts}

Durch die Kontraktion der Gesichtsmuskeln, aber auch durch äußere Einflüsse wird die Haut gedehnt oder zusammengedrückt. Irgendwann lässt ihre Elastizität nach - die Haut kann ihre ursprüngliche glatte Position nicht mehr selbst wiederherstellen. Dermalfiller verjüngen und doch können sie dem Gesicht bisweilen auch einen Teil seiner Schönheit rauben nämlich seine Beweglichkeit. Teosyal ${ }^{\circledR}$ RHA hingegen ist ein auf Hyaluronsäure basierendes Faltenunterspritzungsmateri- al, das erstmals die Haut und das Gewebe bei jeder Bewegung unterstützt und so die Vitalität und Elastizität bewahrt.

Die Teosyal ${ }^{\circledR}$ RHA Filler wurden nach einem patentierten Vernetzungsverfahren entwickelt, welches die natürlichen Eigenschaften der Hyaluronsäure-Moleküle bewahrt. Deren lange Ketten können sich selbst in einem beweglichen 3D-Netzwerk organisieren und besitzen dadurch eine hohe viskoelastische Kapazität und Haltbarkeit. Die spezielle Vernetzungstechnik benötigt deutlich weniger Butandioldiglycidylether und kann so die ursprüngliche Länge und natürlichen Verbindungen der Hyaluronsäure-Ketten erhalten. Dadurch entstehen Gele mit hoher Reinheit, die der natürlichen Hyaluronsäure in der Haut sehr ähnlich sind.

Sobald das Gel injiziert wurde, glättet es die Falten von innen, unterstützt das Gewebe und gibt der Haut ihre Elastizität zurück. Das Produkt ist nicht spürund fühlbar, sondern wird eins mit der dermalen Struktur. Der Filler eignet sich besonders für die dynamischen Bereiche wie etwa Mundregion, Wangen, Nasolabialfalten, Stirn, Krähenfüße, aber auch für Hals und Dekolleté.

Nach Informationen von Teoxane Germany 